Please do not remove this page

RMIT

UNIVERSITY

\title{
Troubling talk: assembling the PhD candidate
}

Mewburn, Inger

https://researchrepository.rmit.edu.au/esploro/outputs/9921858393201341/filesAndLinks?institution=61RMIT_INST\&index=null

Mewburn, I. (2011). Troubling talk: assembling the PhD candidate. Studies In Continuing Education, 33(3), 321-332. https://doi.org/10.1080/0158037X.2011.585151

Document Version: Submitted Version

Published Version: https://doi.org/10.1080/0158037X.2011.585151

Repository homepage: https://researchrepository.rmit.edu.au

(c) 2011 Copyright Taylor and Francis Group, LLC.

Downloaded On 2023/04/26 11:35:06 +1000

Please do not remove this page 


\section{Troubling Talk: assembling the PhD candidate}

When PhD students complain about problems with their study progress there can be a tendency for those who are listening to seek remedies. This urge to fix assumes that there are problems and that 'troubles talk' is evidence of a sick research culture. This paper argues that such a one dimensional reading fails to attend closely to the academic identity work which is done when students talk about $\mathrm{PhD}$ study with each other. The concept of identity work has become a useful way of thinking about the nature of $\mathrm{PhD}$ study in the production of thesis texts (Kamler and Thompson, 2007; Dunleavey, 2003), the management of supervisor student relationships (Johnson et al, 2000) and in the practices of everyday life (Barnacle and Mewburn, 2010). This paper extends this work by analysing various instances of $\mathrm{PhD}$ student 'troubles talk' using tools from actor network theory. It concludes that troubles talk can be understood in multiple ways, including as a type of informal learning practice, and goes on to explore some possibilities for working with 'troubles talk' in a productive way.

Keywords: research education; informal learning; actor network theory

\section{Introduction}

Within the literature on research education there has been a growing fascination with what we might call 'academic identity work': the processes through which a scholarly self is assembled. Identity work has become a useful way of thinking about the nature of $\mathrm{PhD}$ student work and study, particularly in the production of thesis texts (Kamler and Thompson, 2007; Dunleavey, 2003), the management of supervisor student relationships (Johnson, Lee \& Green, 2000) and in the practices of everyday life (Barnacle and Mewburn, 2010). In this paper I start to connect the notion of $\mathrm{PhD}$ student identity work with processes of talk and interaction. In particular I treat various instances of $\mathrm{PhD}$ students complaining about their work as a form identity work in action.

The proposition in this paper is that telling stories about the self is one way in which $\mathrm{PhD}$ student identity is crafted. In his seminal study of narratives told by the terminally ill, Frank (1995) highlights that stories told of the body in distress are a 
way of "drawing maps and finding new destinations“(pg 53). Telling of stories about the self, particularly of the self in some sort of distress, is a way of managing and building the self. Frank's work alerts us to the fact that in telling a story of the self, a sick person (re)presents themselves in new ways depending on the audience and the context in which they find themselves.

While PhD student complaining is sometimes taken as evidence of a 'sick' research culture, such a one dimensional reading wipes away all the interesting questions and does not pay attention to the interesting nuances in such talk. This paper begins to explore the possibilities which arise in attending closely to this talk and using the power of talk to assist PhD students in the crafting of a scholarly self.

To this end, rather than analyze discrete parcels of speech, as is common in traditional conversational analysis, I have worked up a set of stories based on observed episodes of 'troubles telling' (Jefferson, 1984) amongst PhD students. This narrative approach preserves the situated complexity of the incidents of speech by paying attention to the conditions under which they are produced and who is listening. Rather than provide one interpretation of the events, I work to find simultaneous and even contradictory meanings in each story, looking to Actor Network Theory (ANT) for tools of analysis.

\section{Troubles Talk}

Building on the early work of Harvey Sacks, Gail Jefferson (1984) analysed the structure of talk about troubling events in conversational pairs. Jefferson claims that telling troubles and hearing troubles is part of the social affiliation process which can make it a difficult conversational task. Managing the presentation of self in these stories can be a complex task. By telling a story about trouble we have experienced, especially one which involves some kind of accident or emotionally difficult incident, 
we place the recipient of our trouble story in a difficult position because they have to respond with the correct level of 'care'. Due to their difficult nature, and toll on the listener, troubles are not normally presented 'cold' within a conversation.

Jefferson outlines a sequence of stages in troubles telling during which the trouble is introduced by the troubles teller and then dealt with by both parties. She identifies a general shape of the troubles telling sequence: some kind of lead up to the announcement of trouble (where the listener is offered the chance to take up the trouble or not), before the trouble is discussed in more detail (a 'workup' phase) where the listener can exhibit "affiliation" with the troubles teller. Jefferson reports listeners doing this in a number of ways such as diagnosing the trouble, making prognoses, reporting other relevant experiences and suggesting remedies. This work up is followed by a wind down phase where both conversational partners begin to disengage from the troubles talk in a respectful way.

Although this sequence may not always be strictly adhered to, Jefferson styled troubles talk as a repertoire on which people can draw to do identity work by positioning themselves in relation to the troubles they have heard. Troubles talk has been widely taken up in psychological literature, where it tends to be treated as a counselling tool or as a way of understanding affiliation in gender and age relationships.

However the following story, the first I will offer, unsettles Jefferson's singular reading. Last year I was called in to do a workshop for research students who were part of a group which meets regularly to talk about qualitative research methods. One of the students had invited me in to talk to the group about issues of identity in $\mathrm{PhD}$ writing, a workshop I had run many times which drew heavily on the work of Kamler and Thompson (2007) discussing scholarly identity and writing practices. 
In the 20 minutes immediately following my presentation there was a lively discussion amongst the group. Candidates connected the issues I had raised with their own personal experience of doing a $\mathrm{PhD}$. They talked eloquently about the tensions involved in taking on and acting in the role of 'academic', both in public life and in writing. They wondered about the tacit rules of their different academic communities and how one might recognize them - or not. Then they started to discuss how this new identity of 'scholar' might be manifested and how it might conflict with other identities that they had assumed over what was, for many in the room, a long working life.

Various group members began to unearth stories of prior experiences and reexamine them publicly in light of the discussion. This process started to reveal quite deep personal issues when the mentor, an academic of some considerable standing, interrupted the session to express what she termed as her "concern" with the direction that the conversation was taking. She claimed that she had noticed that $\mathrm{PhD}$ candidates often indulged in this kind of "whinging, when they got together as a group and that she believed it promoted a culture of victim-hood. The room went silent as she exhorted the students to remember to be grateful for the opportunity that post graduate study gave them to stretch their intellectual muscles - why, some were even paid a stipend for this privilege.

Seeing that none of the students were going to speak, I tried to argue with the mentor that airing private concerns in public can be valuable, if only to create the opportunity to recognize that others might be feeling similar emotions. I highlighted the research of Lovitts (2001) who claimed that 'pluralistic ignorance', or failing to realize that one is not alone in one's struggles, is of the key reasons that candidates tend to "leave in silence" thinking that they were not up to the task of research degree 
study. I'm not sure if I managed to convince the mentor of my point of view and I left, feeling more than a little discouraged.

However, later at my desk, I received a series of emails from students who were in the room, thanking me for the workshop and telling me more of the experiences they had gone through. One claimed she had been disappointed that they had not been able to tell her own stories because their mentor had "closed down" the discussion prematurely. She claimed that the accusation of whinging made her realize she was privileged and feel ashamed about "complaining". The problem was now she didn't know "how to feel". Were her struggles not a valid source of anxiety - should the anxiety really be felt as pleasure? What about if she can't feel pleasure in the struggle - should she leave?

Another student told me she always appreciated the opportunity to listen to others tell their stories because she learnt from them, sometimes about how to avoid similar mistakes. This student told me that she felt as if the mentor, whom the student admired greatly for her scholarly capacity, seemed to have "lost touch" with the immediate issues and concerns of PhD students and what "made them tick". Yet another student wondered if I was a threatening intruder whom the academic mentor was working to "silence". She said she admired the way I defended myself without being hostile, while wryly noting that she was only game enough to add her voice after the fact.

This incident made me realize that troubles talk amongst $\mathrm{PhD}$ students is a phenomenon that is little discussed and poorly understood even by those of us who work with this group all the time. While I had felt that troubles talk had a place as a way to 'vent' one's frustrations and learn that one was not alone, these students were telling me something different. To them troubles talk was a form of solace at the same 
time as a source of knowledge about how to orient oneself in one's practice as a researcher. However, to the academic mentor at least and perhaps others in the room, troubles telling was 'whinging' which acted to obscure the pleasures of scholarship. So which version of the reality of troubles talk was true?

The only answer can be: all of them.

\section{An actor network take}

To start to make sense of this muliplicity, we can examine this moment using an Actor Network theory approach. Elsewhere, with Robyn Barnacle (2010), I made a case that $\mathrm{PhD}$ candidature could be understood as an actor network. Following the work of Robin Usher and Richard Edwards (2007), we argued that a research student can be understood as a 'knowing location' in a network built from relations: with other knowers, such as the supervisor, peers and colleagues as well as with knowledge artefacts, such as journal articles, books and databases.

As an empirical approach, ANT attempts to overcome the old sociological dilemma of structure and agency by positing that structure and agency arise together and are co-implicated in each other's production. The aim of an ANT investigation is to explore what work, by human and non human actors, produces what effects. Effects are often assumed to be facts: 'the research culture' is one effect in this paper; 'the PhD student' and 'the university' are others. In this paper I treat these 'facts' as actor networks, or assemblies of people and things which do various kinds of work. This empirical stance implies a relativist ontology; there is not one singular 'research culture' which is true and real, but multiple practices and actions which assemble a research culture differently, in different times and places because actor networks are never singular, but multiple and over lapping. 
Troubles talk is part of the assembling work performed by people and things which helps to hold research cultures together - or not. There is always the possibility of resistance. A key plank in the ANT approach is that networks are fragile; things and people can 'escape'. It takes work to 'assemble' any $\mathrm{PhD}$ candidature actor network and this work is not just done by the student. Reading, writing, doing experiments, presenting work etc all depend on things as much as on the student's on abilities, as John Law puts it:

"If you took away my computer, my colleagues, my office, my books, my desk, my telephone I wouldn't be a sociologist writing papers, delivering lectures, and producing "knowledge". I'd be something quite other -- and the same is true for all of us." (Law, 1992, pg 4)

But identities, because they emerge out of network relations, are never fixed or straight forward. I talked in this previous paper about the way that a book lying on the counter enabled me to experience the simultaneous identity of mother and student in my kitchen. Of late ANT scholars have started to attend more closely to this kind of multiplicity. Different networks perform different realities into being and any given actor's enrolment in any network is only ever partial. What we call Family, Community, Workplace all are different actor networks which overlap and oftentimes complicate the $\mathrm{PhD}$ candidate actor network which students are simultaneously enrolled in.

In other words, while work is done by animate and inanimate to assemble the PhD candidate actor network, enabling a PhD student identity to emerge (reading, writing, doing experiments etc) other actor networks may be interfering with this assembling work. We are always caught up in multiple network relations. Partial enrolment is many networks is inescapable because these networks emerge in the process of everyday life: being part of a family with children and ageing parents, 
participating the workplace, taking part in a religious community, engaging with hobbies etc. These other actor networks produce offer $\mathrm{PhD}$ student other identities (parent, worker, Lutherian, train set enthusiast) - in fact the identity of 'student' might be the most difficult to maintain at certain times, as many part time students will attest.

If the work done to assemble the $\mathrm{PhD}$ candidature actor network is successful, various resistances have to be overcome. Overcoming resistance takes work and this can be done by all kinds of actors: libraries make the right books available; security card readers allow access to study spaces; photocopiers, printers, phones and computers stay connected to the internet; childcare workers don't strike; the interest rate market remains calm; the new train set catalogue ends up on the bottom of the mail pile etc. If all this work is done the $\mathrm{PhD}$ candidate actor network quietly hangs together and the student identity is able to be performed with relatively little fuss. All this work that is performed to hold the network together tends to disappear from view, only to become visible when the $\mathrm{PhD}$ actor network starts to break down or fails altogether.

We could think about identities as lying latent in any $\mathrm{PhD}$ actor networks ready to be taken up, but sometimes they might be more present and available than others. Consider the ritual of $\mathrm{PhD}$ confirmation. The confirmation process presents the student with a set of resources - in particular the invitation to take the stage and perform their research for others while the audience temporarily agrees to be silent. The candidate's presentation of a struggling self may be done far differently here, in front of senior academics have power to determine who should stay and who should go, than it will be done in, for instance, a kitchen. In this moment the $\mathrm{PhD}$ candidate actor network makes the identity of "student" - learner and 'unknower' - available at 
the same time as 'professional academic' - a knower and teller, rather than a learner. This identity 'jostling' can be a source of tension and conflict depending on how it is managed, which is why troubles talk is particularly interesting. Troubles talk can emerge in boundary spaces where doctoral identity is precarious, but this doesn't necessarily mean that everything is going to fall apart. Quite to the contrary - troubles talk may do work to keep the network together. I will discuss this idea briefly, by way of another story.

\section{Sacha's story}

In early 2009 I was asked by a group of students from a famous medical science research institute to go on retreat with them. It seemed a good opportunity to parlay my skills in presenting doctoral education issues in return for a nice trip to the country and the chance to get to know a group of science students with whom I did not have much contact. The students came from a number of universities and worked in a large facility joined to a local hospital.

A flurry of emails and phone calls quickly established that Sasha could drive my car-free self down to the country. The drive was long, so Sasha and I chatted about the life of a research student in a large laboratory. Sasha was a new $\mathrm{PhD}$ student but told me that she was older than many of her comrades and had worked for over a decade as a lab tech. As a result she was extremely skilled in manipulating the tools of the trade and talked about the difficulty of pursuing her own research while others pestered her for help with their experiments.

While Sasha was confident in her technical skills she was clearly troubled on a number of other fronts. She was worried that too much time as a lab tech had affected her ability for creative thinking and theory building. Her family relationships (especially her position of the last daughter remaining at home in a large Greek family 
with ageing parents) precluded long hours in the lab. She did not participate in what she called the "drinking and partying" in order to "have a life" (which is why she was free to drive me to the research student "sleepover"). During the drive I was struck by what seemed to be a consuming worry on Sasha's part that the other students, even the more established research fellows, would steal her research topic and ideas away from her. Just before we got out of the car Sasha expressed her gratitude to me for listening to her 'problems' which she claimed she couldn't share freely with her peers.

I wondered if Sasha's social exclusion was contributing to her paranoia, but after spending a day with the whole cohort I decided that Sasha was less paranoid than many of her fellow students and was not really an outsider at all. During my presentations I was regularly interrupted by questions relating to plagiarism by supervisors and how to deal with it; other questions concerned worries about how and when to publish such that ownership was established and other, remote researchers wouldn't 'steal' a student's ideas. After the presentation several students approached me with accusations of stealing by their supervisors or their fellow students.

Even casual conversation seemed fraught with these tensions and rivalries. Over lunch I sat on a table with the few women at the retreat whose 'shop talk' was a revelation into the inner workings of this community. The talk happily mixed up the professional and the personal: failed experiments were discussed along with failed relationships, troubles with supervisors, lab techs or funding regimes while Sasha stayed mostly silent. The troubles telling in this conversation was obviously about others as well as the self, but the most interesting feature of the conversation was the presentation of an active and managing self in the talk. This shop talk seemed to be a means to managing one's position in a highly complex pecking order, the rules of which I couldn't begin to understand. 
After listening in bemusement for about half an hour I asked the women about the purpose of their shop talk. They laughed and told me that their "gossip" was an important way of knowing "what was going on". This "knowing" seemed to involve who was doing what with whom, getting the materials they needed for their experiments, building on the knowledge of others and making sure that others (outside of the immediate conversation circle) did not have "the jump" on them (that they were not close beating them to some discovery).

Troubles telling can be a good way of tapping the collective wisdom on a group; Jefferson (1994) shows it has built in mechanisms for eliciting advice from others. However this troubles talk, in contrast to my previous example, actively 'othered' people who were not on the 'inside' of this troubles telling clique. Troubles talk was working here to help students to 'place' themselves within a complex world, learn about what was "going on" in order to maintain or improve that place as well as create an 'inside' and an 'outside'.

Sasha's discomfort in her research world was much clearer after listening to this troubles talk. Sasha remained mostly silent during this troubles telling, but she was able to listen to it and was occasionally asked a question by the others in the group so she was not entirely an outsider. Most of these questions seemed to pertain to her skills as a lab tech. While Sasha had presented herself as to me as tightly enrolled in her family network and therefore on the outer because she could not socialise as easily, it seemed to me that the identity of daughter did not cause as much trouble as the identity of lab tech.

We might assume that Sasha's lab skills, since they were so easily 'transferable' would prove to be an asset in her transfer into being a student-scientist. These lab tech skills put her in a position of being 'used' at the same time that it gave 
her a certain status as a 'knower' in the amongst the student novices and therefore a way of being on the 'inside'. If self narratives are a form of 'identity work' as Frank asserts, the way Sasha presents her feelings, motives and actions in her stories about herself will be shaped to the situational context and the audience at hand. Whereas telling her story and presenting a less competent self to an outsider like myself was easy, telling her troubles to her fellow students and thereby troubling her competent identity seemed to be much more difficult.

Sascha's story starts to hint at how the place in which troubles talk done colludes with and enables the emergence of different kinds of troubles talk. A car is a different place than a table with colleagues. In the relaxed atmosphere of the student sleepover the identity of friend / lover / comrade was perhaps more available than scientist-student because the requisite materials implicated in this identity (lab spaces, samples, refrigerators) were not present. Web spaces and physical spaces where the participants already know each other are particularly conducive to troubles telling.

Paying attention to the circumstances of troubles talk, where and how it is done, can show us how these various identities might gain coherence (or not) and how they might be connected with different forms of learning. I will illustrate this by way of another story.

\section{Kitchen Stories}

Jewel is in the last couple of weeks of submitting her thesis. She participates regularly in the social networking site 'Facebook' where she is 'friended' to a number of past and present PhD students. The friends can post and comment on each others' status updates; Jewel mostly posts updates on her thesis progress. In the comments threads that follow Jewel's updates we can see evidence of Jefferson's troubles telling sequence in action over an extended period of time. 
Jewel shares troubles while her friends and family variously diagnose the trouble, make prognoses, report other relevant experiences and suggest remedies. In one post she announces: "You know you are ready to submit when..... your supervisors are appearing in your dreams chanting "you're never going to finish...muhahahah!!" well that's one way to get me up early! ". In response to Jewel's post a friend, who has already completed their $\mathrm{PhD}$, reports a relevant experience by commenting : "haha, I wasn't able to sleep in at all the last couple of weeks :) anxiety...”. Another friend who has finished her degree light heartedly suggests a remedy: "I can now prescribe something for that...". A family member diagnoses Jewel's trouble and makes a reassuringly positive comment on her ability to finish: "I dislike your bad dreams - you must be anxious is all.... So proud of you - all the best for the end stretch". Similarly a friend who shares Jewel's physical office space offers sympathy: "Hi, take it easy, there is nothing we can't pass through...".

Jewel can mobilise this online space in a very practical way as well, using it as a resource for solving problems she is encountering in her research. In a subsequent post she asks: "To my PhD buddies...I'm having trouble formatting my Table of Contents...anyone at uni with a spare 15 minutes to help me out??". Noting the time on her plea is early morning, and that no one has replied to her plea by the evening that I log in I offer my help. Jewel shares the exact nature of the problem in a subsequent post and I track down the relevant notes, sending them through to her in email.

If Facebook is one 'safe space' for Jewel to tell troubles, there are others. Jewel is studying at the University of Melbourne where, in 2007 the Faculty of Architecture, building and planning refurbished half of the $4^{\text {th }}$ floor of their building to accommodate their 100 odd research students. The new office was open plan and 
arranged in a series of cubicles, much like an ordinary office space. The red walls through the door in Figure 1 marks out what the research students called the 'pods' a cubicle holding four research student desks and computers.

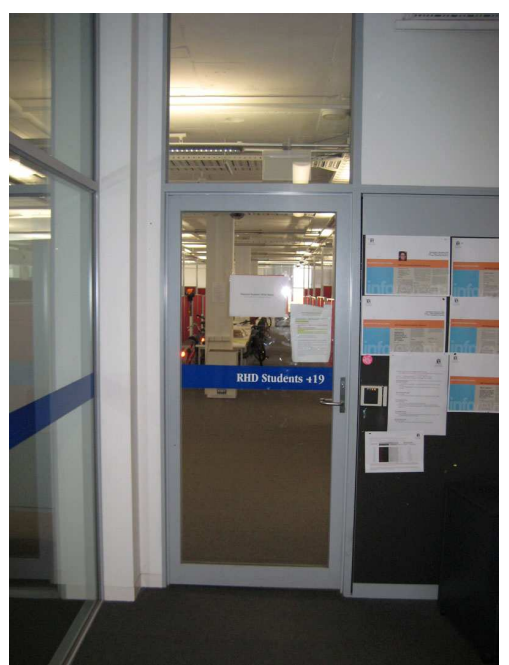

Figure 1. The door to the pods

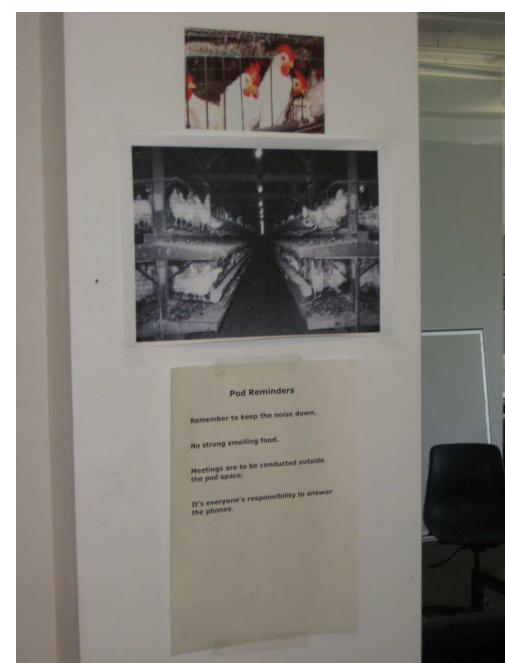

Figure 2. Notes to other inhabitants

The layout of the room is not conducive to every individual's work habits.

Tables down the centre of the room contain communal telephones, but these are rarely used because they are too disruptive to others who are studying. Some evidence of resentment of this open plan environment can be seen in the pictures of battery hens which have been stuck on a column next to the door (fig 2). A note underneath reminds all the students that - making any sort of excess noise (or smell) is a social faux pas.

The space provided for research students does not properly acknowledge that many have a dual identity as working academics, parents, friends and lovers. Being a $\mathrm{PhD}$ student is not like being an undergraduate who turns up to a classroom and then leaves - in this case the close cohabitation means that all identities have to be performed in the same space - which cannot hold this excess without causing breakdown (conflict, arguments and therefore the inability to work). 
As a consequence the adjoining kitchen has to do a lot of what I will call after the work of Leigh Starr (1994) "articulation work". This is work that enables the pod actor network to stay together. In this kitchen space lunch was had, drinks were poured, practice presentations were held, relationships were tended through private telephone calls and impromptu under graduate classes were held. Meetings of the local student union branch 'Space Cadets' took place in the kitchen.

A large meeting table and casual couches were provided along with a fridge, microwave and sink. The notice board along one wall contained pictures of all the students who occupied the pods as well as several photocopies of the website $\mathrm{PhD}$ comix' and a well thumbed copy of Mullins and Kiley's paper 'It's a PhD not a Nobel Prize' (on the subject of how examiners approach assess a PhD thesis.
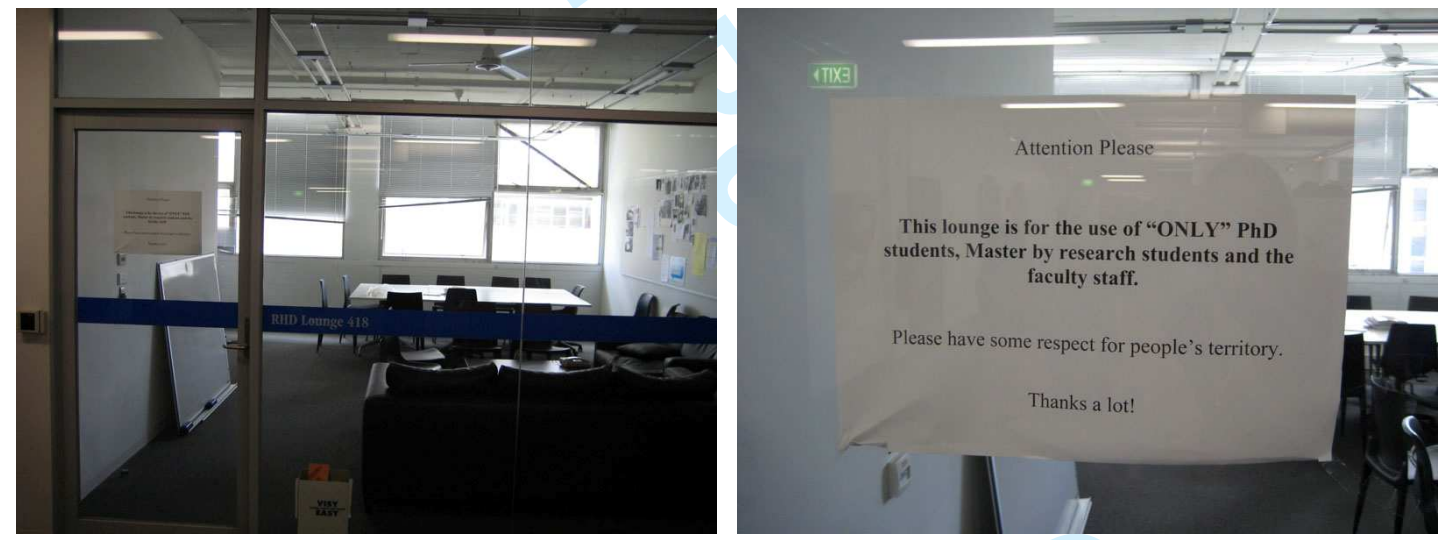

Figure 3 The Post Grad Research Student Kitchen in the Architecture, Building and planning faculty (ABP), University of Melbourne and a close up of the notice on the door.

Unlike the pod space, the kitchen door was not locked during the day and had to be zealously guarded from incursions by undergraduates by means of a notice stuck to the door (Fig 3). Eventually however the kitchen could not 'hold' all this academic work and the research students were forced to 'make' a student consultation space in 
the adjacent foyer by scavenging left over furniture to make an ad hoc consultation area just outside their kitchen door (Figure 4).

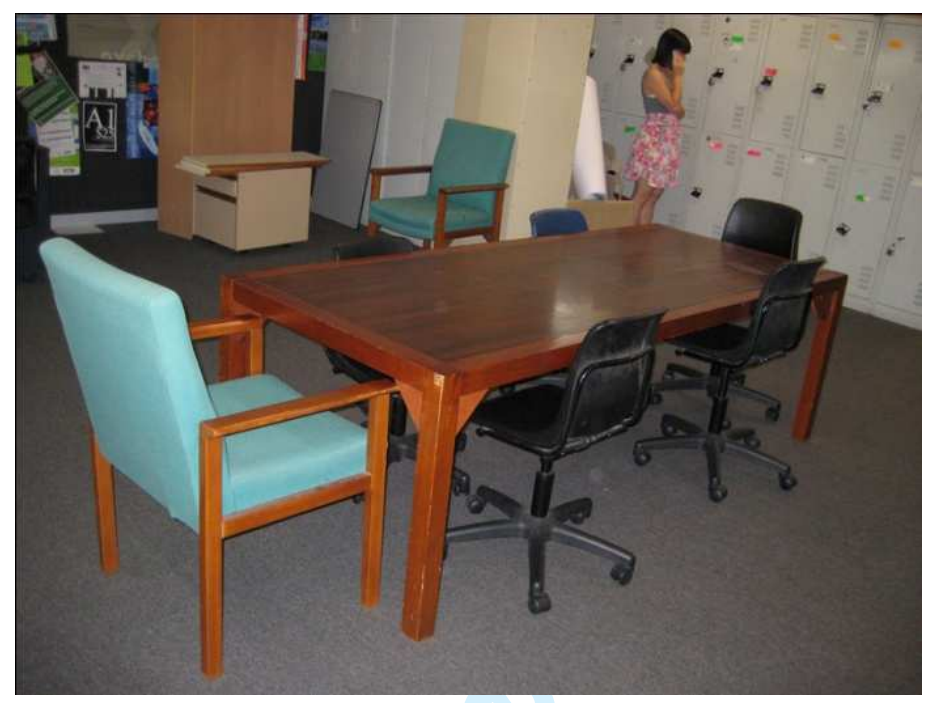

Figure 4 A makeshift consultation area for research students

The physical space of the kitchen and the office, as well as the servers and international networking infrastructure all do work to help this $\mathrm{ABP} \mathrm{PhD}$ student actor network hold together. The troubles talk on Facebook and in the kitchen had the flavour of student advocacy and support as well as a place for informal learning to take place.

There is some evidence in all these stories that troubles talk is implicated in informal learning. Sasha and her colleagues learned who was up to what with whom while the architecture students shared troubles with writing and supervisors over lunch in their kitchen. The students in the workshop in the first story recognized that the stories of others were a good way to learn - often about what not to do oneself.

\section{Conclusion}

So far, troubles talk is emerging as a complex set of practices, done differently in different places and times. In troubles talk multiple identities are fashioned, managed, reworked - and resisted. Further, special places are found to be quietly 
complicit in the work of troubles talk. In-between places: country retreats, kitchens, hallways, the internet seem to gather troubles talk in particularly generative ways. All this short paper can hope to achieve is to start to map some of this territory.

Students clearly 'do affiliation' in troubles talk just as Jefferson claims, this kind of troubles talk produces a certain subject position (one of us - or not one of us). Troubles talk also acted as a way of learning about and managing one's place in the research world and how to do research work. Sometimes 'identity jostling' caused tension and threatened the identity of 'student' - yet the these other identities (friend, lover, parent, worker) could not be excluded or wiped away because the student identity relied on the work done in these other networks.

Obviously troubles talk needs to be treated with care by those whom participate in it. The freeform troubles talk amongst the science students fostered competition as well as affiliation; there was clearly a chance to be othered and marginalised. But interference has the potential to produce 'collateral realities' (Law, 2005). The humanist impulse in education would see this othering as a 'bad' which has to be managed - but this might come at the cost of wiping out the good work it does to help students hold on to their place in their research world. The mentor's remark about the 'culture of victimhood' is one example; the remark was true enough that it produced an uncomfortable silence and derailed the learning which was obviously occurring through the talk. Those who would have the urge to interfere might be advised to remember that stories will be different each time they are told because the self is being performed anew - there is always the possibility that the troubles telling is performing a stronger scholarly self into being as well as a more fragile one. 
For people working in research education, working with troubles talk might provide new angles for developing pedagogical interventions. For a number of years my university, RMIT has run a discussion forum program for research degree students ${ }^{\mathrm{ii}}$ which has recently been rebadged the 'On Track' Program. The purpose of this series of workshops is to provide information and build so called 'generic skills' such as writing and presentation.

The pedagogy informing the On Track program is explicitly based in conversation. Candidates are presented with issues or scenarios and asked to workshop ideas in a small group format. Importantly the forum is open to candidates from all disciplines. The feedback to this program over the years has indicated that students highly value the opportunity just to talk with each other and yet often lack such a forum in which talk is the main event.

This program and others like it break open the usually tightly closed 'black box' of supervision and disciplinary practices. Through talk and sharing stories with candidates from throughout the university, students are exposed to radically different practices and assumptions and are able to critically examine the practices in their area in light of these. Often the scenarios students are asked to workshop involve case studies of students in difficulties which enables them to briefly experience the role of supervisor.

This paper cautions us to listen carefully to what is being said when $\mathrm{PhD}$ students talk about their study and to pay more attention to where the saying takes place. More research of this sort into PhD student culture is important. Despite consistent attempts to put numbers on satisfaction candidates feel with their 'research environment', such as Australia's Post Graduate research experience survey (PREQ), we still know very little about what makes PhD student communities 'tick'. Like all 


\section{References}

Barnacle, R. and Mewburn, I. 2010. Charting an Actor-Network Theory approach to doctoral learning. Studies in Higher Education 35 (4): 433 - 444

Dunleavey, P. 2003. Authoring a PhD: how to plan, draft, write and finish a doctoral thesis or dissertation. London: Palgrave Macmillan.

Jefferson, G. 1984. On the organization of laughter in talk about troubles. In J.M. Atkinson and J.C. Heritage (Eds.) Structures of social action: Studies in conversation analysis (pp.346-369). Cambridge, UK: Cambridge University Press.

Johnson, L., Lee, A. \& B. Green. 2008. The PhD and the Autonomous Self: Gender, rationality and postgraduate pedagogy. Studies in Continuing Education 5(2): $135-147$

Kamler, B. And Thomson, P. 2007. Helping Doctoral Students to write, New York: Routledge

Law, J. 1992. Notes on the Theory of the Actor-Network: Ordering, Strategy and Heterogeneity. Systems Practice 5: 379-393.

Law, J. 2009. Collateral Realities, Draft version of 29th December 2009, available at http://www.heterogeneities.net/publications/Law2009CollateralRealities.pdf Lovitts, B. E. 2001. Leaving the Ivory Tower. New York: Rowman and Littlefield Publishers.

Starr, S. L. and Strauss, A. 1999. Layers of Silence, Arenas of Voice: The Ecology of Visible and Invisible Work. Computer Supported Cooperative Work (CSCW) 8: 9-30

\footnotetext{
i 'Whinging' is a colloquial term in Australia which the Oxford English Dictionary (Australian ed) defines as 'to grumble peevishly'. It has a slightly different meaning than 'whining' - complaining which is done in a more querulous and feeble way. The primary difference between whining and whinging is that the whinger does not necessarily expect a direct answer or response.

ii This forum was initiated after a report into the research environment by Dr Robyn Barnacle in 2003 revealed that students wanted a chance to talk with their peers about the issues that research students faced. Dr Barnacle set up and ran the forums for a number of years before I became involved in 2005
} 